\title{
CRIMES CONTRA A FAUNA
}

Cláudio José Donato ${ }^{1}$ Irene Caires da Silva ${ }^{1}$, José Luís de Lima Astolphi ${ }^{1}$, Joselene Lopes Alvim ${ }^{1}$, Maira Rodrigues Uliana ${ }^{1}$, Taís Muller².

${ }^{1}$ Universidade do Oeste Paulista - UNOESTE, Presidente Prudente, SP. ${ }^{2}$ Universidade Estadual de Maringá - UEM, Umuarama, PR. E-mail: claudio.donato@hotmail.com.

\section{RESUMO}

A preservação do Meio Ambiente foi legalmente negligenciada por muitos anos na história mundial. No Brasil, os primeiros passos foram dados com a Constituição Federal de 1988, em seu art. 225. Entretanto, somente com a promulgação da Lei $9.605 / 98$, que a proteção foi devidamente disciplinada a fim de tornar mais apropriada e abrangente a legislação vigente, unificando a legislação penal em matéria ambiental. Sob esta ótica, o objetivo deste estudo, que é uma revisão de literatura, analisa de que maneira se procede a tutela legal da fauna silvestre no Brasil, de acordo com a legislação vigente. Busca-se demonstrar, por meio de dispositivo das normas legais referente à tutela os animais silvestres, que a proteção destes animais passou por uma evolução histórica em termos jurídicos, chegando aos dias atuais como um instrumento efetivo que garante o direito à vida silvestre.

Palavras-Chaves: Lei 9605/98; crime ambiental; risco a fauna; proteção.

\section{CRIMES AGAINST WILDLIFE}

\section{ABSTRACT}

The preservation of the environment was legally neglected for many years in world history. In Brazil, the first steps have been taken with the Federal Constitution of 1988, in your art. 225. However, only with the enactment of law 9,605/98, that protection was duly disciplined in order to make it more appropriate and comprehensive legislation, unifying the criminal law in environmental matters. Under this perspective, the objective of this study is a literature review examines how legal guardianship is of wildlife in Brazil, according to the current legislation. We seek to demonstrate, by means of legal norms concerning device tutelage the wild animals, the protection of these animals has undergone a historical evolution in legal terms, coming up to the present day as an effective instrument which guarantees the right to wildlife.

Keywords: 9605/98 law; environmental crime; fauna risk; protection. 


\section{INTRODUÇÃO}

Ao examinar a evolução na criação de novas legislações, verifica-se que os animais constituem individualidade dotada de personalidade típica à sua condição, sendo, portanto, também sujeitos de direito. Na dogmática jurídica somente o homem pode ser sujeito de direito, mas essa lógica se inverte quando se fala em direito ambiental, o qual aceita a premissa de que o homem é representante dos animais, em juízo. Desta forma, o direito dos animais é beneficiado pelas mesmas garantias asseguradas aos homens (MILARÉ, 2007). Assim, entende-se que ainda que não sejam pessoas, os animais não deixam de usufruir do patrimônio jurídico que lhes garanta o mínimo para a sua existência (LOURENÇO, 2008).

A partir do que foi exposto, o objetivo deste estudo foi analisar de que maneira se procede a tutela legal da fauna silvestre no Brasil, de acordo com a legislação vigente.

Justifica a realização deste trabalho o fato de ser intolerável para uma sociedade ética e moralmente constituída, a continuidade da exploração indiscriminada e predatória do meio ambiente natural, causando-lhe degradação, em níveis cada vez mais alarmantes, e cuja consequência é o desequilíbrio muitas vezes irreversível, bem como o sofrimento e até mesmo a extinção de várias espécies. Isso significa que é de grande importância social e de interesse profissional, polícia ambiental, uma avaliação mais acurada acerca da abrangência, competência, efetiva aplicabilidade e limitações da Lei 9.605/98 para garantir que a busca da sustentabilidade humana não esteja atrelada somente ao incremento da sua própria qualidade de vida, mas, principalmente, ao respeito a todas as formas de vida.

\section{METODOLOGIA}

Para o desenvolvimento deste trabalho foi utilizada a pesquisa bibliográfica, a qual abrange a leitura, análise e interpretação de livros, periódicos, entre outros.

De acordo com Lakatos e Marconi (2006, p.43), a pesquisa bibliográfica consiste,

no levantamento de toda a bibliografia já publicada em forma de livros, revistas publicações avulsas em imprensa escrita [documentos eletrônicos]. Sua finalidade é colocar o pesquisador em contato direto com tudo aquilo que foi escrito sobre determinado assunto, com objetivo de permitir ao cientista o reforço paralelo na análise de suas pesquisas ou manipulação de suas informações.

Para Duarte e Barros (2009, p.51), a pesquisa bibliográfica "começa na identificação, localização e obtenção da bibliografia de interesse e relevante ao assunto pesquisado, seguindo até a formulação de um texto elaborado, onde é apresentado o que foi absorvido pelo pesquisador". Desta forma, foram pesquisados livros, artigos, com o objetivo de situar e fazer compreender os assuntos e definições acerca do tema do presente artigo.

\section{RESULTADOS}

A fauna brasileira ocupa estatística relevante no contexto mundial da biodiversidade. Tal situação impele o país a adotar normas que priorizem sua proteção, visando o combate à sua destruição e extinção. O dispositivo legal esculpido no artigo 225 , § 1 o da Constituição da República de 1988, contém o fundamento da tutela da fauna brasileira (LEVAI, 2008). Numa visão ampla, o termo "fauna" é utilizado como o coletivo de animais de determinado período geológico, local ou região. No sentido etimológico este vocábulo se origina de uma derivação do latim "faunis" que significa ente mitológico, habitante dos bosques e florestas. Na atualidade se utiliza para significar o coletivo de animais (GODINHO, 2011).

Na perspectiva, para Milaré (2007) a fauna é compreendida como o conjunto de espécies animais de um determinado local (país, região, distrito, estação) e também um dado período 
geológico, que tem o objeto da tutela jurídica priorizada. Godinho (2011) menciona que existe diferença entre reino animal e fauna, sendo o primeiro definido como o conjunto de todos os animais, e o segundo como sendo o conjunto de animais de uma determinada região. Conforme Godinho (2011, p.35), o conceito de fauna é desdobrado em:

a) Fauna Doméstica: conjunto de animais que se tornaram dependentes do homem.

b) Fauna exótica: conjunto de animais introduzido em um ecossistema do qual não faziam parte originalmente, mas onde se adaptam e passam a exercer dominância, e prejudicam as espécies naturais e nativas.

c) Fauna aquática: animais que possuem como habitat o meio líquido.

d) Fauna terrestre: animais cuja existência está ligada ao habitat terrestre;

e) Fauna sinantrópica: conjunto de animais que utilizam recursos de áreas antrópicas de modo permanente ou transitório em seu deslocamento.

f) Fauna Silvestre: abrange o conjunto de animais não domésticos.

Em relação à tutela jurídico penal brasileira que se propõe a preservar e proteger a fauna silvestre, o promotor de justiça Laerte Fernado Levai (2008, p. 32), considera que:

Bem ou mal, tais dispositivos permitem a movimentação da máquina judiciária em favor dos animais, embora as penas corporais possam ser substituídas por prestação de serviços à comunidade, mediante a imposição de tarefas de natureza ambiental que permitam ao infrator, em tese, ressocializar-se ou ao menos se conscientizar de seu erro.

A legislação, no tocante aos ilícitos contra a fauna, se encontra abrigada na Lei no 9.605/98 (BRASIL, 1998), que dispõe sobre as sanções penais de atividades e condutas lesivas ao meio ambiente, que inclui crimes contra a Fauna em seção específica.

\section{DISCUSSÃO}

Os crimes contra a fauna estão previstos nos artigos 29 a 35 da Lei 9.605/98. De acordo com Araújo (2017, p.01), pelo artigo 29, o conceito de animal silvestre, nativo ou em rota migratória, contém a expressão "e quaisquer outras, aquáticas ou terrestres, que tenham todo ou parte de seu ciclo de vida ocorrendo dentro dos limites do território brasileiro".

O legislador não incluiu os animais importados e os que não se adaptam ou não se reproduzem livres do cativeiro, pois a liberdade do animal é fundamental para a caracterização deste como silvestre. Isso constitui um descuido da lei, que ao tentar proteger somente os animais que se achem inseridos no conceito de 'silvestre', deixa em descoberto, pelo artigo 29, aqueles cuja existência ou sobrevivência se encontre dependente de amparo humano, circunstancial ou não. Mesmo que todos os animais (silvestres, domésticos ou domesticados, nativos ou exóticos) estejam sob a proteção do artigo 32 da mesma lei.

Quanto ao aspecto da dependência em especial, a legislação também não faz, neste ponto, nenhuma distinção à característica do cativeiro, se sob os necessários cuidados de criadores e mantenedores sem fins lucrativos, ou se sob os domínios de captores e comerciantes inescrupulosos; mencionando apenas os termos "domésticos" ou "domesticados".

Segundo explicam Lourdes e Miranda (1998, p.15), o elemento normativo do tipo "sem a devida permissão, licença ou autorização da autoridade competente, ou em desacordo com a obtida", traz a caracterização do delito como dependente da existência ou não de um ato de natureza administrativa previsto em legislação específica. Aqui, embora haja a vinculação do cativeiro à documentação legal, pode haver o risco da possível falsificação de documentos, o que não é raro nos casos de exploração da flora. 
Para Ramos (2000), a previsão da Lei de Crimes Ambientais - LCA, sobre a competência concorrente da União, Estados e Distrito Federal legislarem sobre caça, não legitima a legalização de qualquer tipo de caça. Isso significa que deve ser haver consonância do artigo 225, parágrafo primeiro, inciso VII com o artigo 24 inciso VI da Constituição Federal que restringe as modalidades de caça à: de controle, para a subsistência, para finalidade científica (art.14, da Lei 5.197/67) e de animal doméstico que, por abandono, se torne selvagem (art.8o, parágrafo único, da Lei 5.197/67). Entretanto, a LCA não legitima a prática da caça amadorística presente nos dispositivos da Lei 5.197/67.

Isso se justifica porque, através do próprio termo 'amadorística', verifica-se que se trata de atividade desenvolvida por mero "prazer" ou "deleite" em matar criaturas vivas, o que por si só já se configura manifestamente como ato de crueldade e, portanto, como prática vedada pela Constituição Federal.

De acordo com Migliari Junior (2004, p.56), quanto às causas de aumento de pena arroladas no artigo 29 , ressalta-se que:

Algumas delas também estão listadas no art.15, da Lei 9.605/98 como circunstâncias agravantes, razão pela qual se deve atentar para a impossibilidade de utilizá-las como agravantes quando já estiverem computadas na dosimetria da pena como causas de aumento, em obediência ao princípio non bis in idem. Especificamente, pelo art.29, parágrafo 40 , inciso $\mathrm{V}$, da Lei $9.605 / 98$, que determina o aumento da pena de metade se o crime contra a fauna for cometido em unidade de conservação, em algumas hipóteses, poderá ocorrer conflito aparente de normas com o delito de "causar dano direto ou indireto à unidade de conservação" (art.40, da Lei no. 9.605/98).

Nesses casos, a análise do caso concreto é que definirá a tipicidade, principalmente mediante a avaliação da extensão do dano e das conseqüências das condutas tipificadas nesse artigo em relação aos ecossistemas protegidos através da criação da unidade de conservação.

De acordo com Batista (2010, p.14), nos artigos 30 e 31, o legislador capitulou como delitos contra a fauna silvestre a exportação de peles e couros de anfíbios e répteis em bruto e a introdução de espécie animal no Brasil, ambas sem as devidas autorizações ou licenças administrativas. "Não obstante a notória biodiversidade da fauna silvestre brasileira, cuja riqueza obviamente não se limita aos interesses comerciais tipificados no art.30, da Lei 9.605/98", o legislador não atentou para a necessidade da proteção especial de "outros" elementos da fauna silvestre, extremamente cobiçados pelo mercado internacional, como o veneno de cobras, por exemplo. Essa é uma falha da Lei $9.605 / 98$, que deveria ser mais abrangente.

Outra falha da referida Lei refere-se à carência de um tipo específico para a criminalização mais rigorosa no que diz respeito ao tráfico de animais silvestres ao exterior. Batista (2010) afirma que é o tráfico de animais silvestre a terceira maior atividade ilegal do mundo, perdendo apenas para o tráfico de armas e drogas. No Brasil, essa atividade ilegal movimenta cerca de 1,5 bilhões de dólares por ano e são retirados da natureza cerca de 38 milhões de animais anualmente; dos quais, de cada dez retirados de seu habitat natural, apenas um chega às mãos do comprador final, nove morrem durante a captura ou na manutenção em condições cruéis ou ainda no transporte ilegal.

Considerando que ao caso específico do tráfico de animais silvestres, pela LCA não há repressão penal adequada à gravidade dos crimes, já que as penas são extremamente brandas, o que ocorre é um verdadeiro estímulo à reincidência dos traficantes.

Para Batista (2010), graças à desproporcionalidade das penas previstas nos tipos que integram a seção dos crimes contra a fauna quando comparamos as penalidades cominadas nos 
crimes relacionados aos atos de caça com os de pesca, os traficantes de animais silvestres preferem optar por uma transação penal ou uma suspensão condicional do processo ou até mesmo pelo risco de condenação a uma pena extremamente baixa e suscetível de prescrição a deixarem de auferir os altos lucros que o crime proporciona.

Essa comparação procede quando se comparam os artigo 34 e 29 da Lei 9.605/98, pela qual a pena máxima é de três anos àqueles que pescam em período proibido ou em local interditado, enquanto as penas para os sujeitos que matam espécime da fauna silvestre não pode ser superior a um ano, salvo se presentes alguma das causas de aumento desta.

Pelas explanações de Martins (2008), nos crimes contra a fauna silvestre, há inúmeras incertezas quanto à reparação do dano ambiental em virtude das grandes dificuldades de constatação efetiva deste e na ausência de critérios oficiais e específicos de avaliação e valoração dos danos ambientais provocados pelas condutas tipificadas.

Os artigos 32 a 35 são bastante abrangentes em seus termos específicos e menos polêmicos. Entretanto, por todos os artigos da LCA analisados, não há possibilidade da ocorrência, em nenhum caso, mesmo sob circunstâncias agravantes, de sanção penal superior a cinco anos de reclusão. Esse deve ser considerado o fator crítico da menciona Lei, especialmente em se tratando da garantia de sua efetividade, uma vez que tal brandura tem servido de facilitador para que os crimes contra a fauna, ocorrendo, não sejam punidos, nem tão pouco sejam evitados.

\section{CONSIDERAÇÕES FINAIS}

Ao cumprir o objetivo deste artigo de analisar de que maneira se procede a tutela legal da fauna silvestre no Brasil, de acordo com a legislação vigente, foi possível compreender que a Lei 9.605/98 é um marco histórico na defesa jurídica da fauna silvestre nacional, pois sistematizou a matéria e consolidou a inclusão dos animais dentre os bens de natureza difusa, em contraposição à tradicional classificação da fauna silvestre como bem público ou privado. Entretanto, é latente a necessidade de aperfeiçoamento e de regulamentação de novos critérios para a solução das obscuridades e injustiças que ainda se configuram no momento da aplicação das normas penais.

Cabe ressaltar ainda que a própria Constituição Federal, em seu artigo 225 garante que todos possuem direito ao meio ambiente ecologicamente equilibrado, sendo um bem de uso comum do povo e essencial à sadia qualidade de vida, impondo-se ao Poder Público e à coletividade o dever de defendê-lo e preservá-lo para as presentes e futuras gerações.

Tendo em vista que a Lei no 9.605/98 é uma ferramenta de cidadania, cabe a todas as pessoas exercitá-la por meio do seu amplo conhecimento e da vigilância constante. Assim, é direito e dever de toda pessoa pedir providências ou levar ao conhecimento dos órgãos competentes os crimes praticados contra a fauna e contra o meio ambiente como um todo.

Nesse diapasão, conclui-se que os crimes ambientais em relação à fauna devem ser combatidos com todo vigor das normas penais, por meio da legislação própria bem como de acordo com o amparo dos princípios do Direito Ambiental. Só assim o Brasil poderá proteger e conservar a sua diversidade biológica, antes que nada mais reste para ser protegido.

\section{REFERÊNCIAS}

ARAÚJO, Ivan Vieira de. Considerações acerca do Direito Penal Ambiental. Disponível em: <http://www.conteudojuridico.com.br/artigo,consideracoes-acerca-do-direito-penalambiental,29251.html>. Acesso em: 03 ago. 2017.

BATISTA, Eloanderson Dantas. A eficácia das sanções penais aplicáveis aos crimes contra a fauna. Conteúdo Jurídico, Brasília-DF: 27 set. 2010. Disponível em: <http://www.conteudojuridico.com.br/artigo,a-eficacia-das-sancoes-penais-aplicaveis-aos-crimescontra-a-fauna,29104.html>. Acesso em: 03 ago. 2017. 
BRASIL. Constituição (1988). Constituição da República Federativa do Brasil.

Brasília: Senado Federal, 1988.

BRASIL. Lei no. 9.605, de 28 de fevereiro de 1998. Brasília, DF, 1998.

BRASIL. Presidência da República. Casa Civil. Subchefia para Assuntos Jurídicos. Lei no 9.605, de 12 de Fevereiro de 1998. Dispõe sobre as sanções penais e administrativas derivadas de condutas e atividades lesivas ao meio ambiente, e dá outras providências. Disponível em

<http://www.planalto.gov.br/ccivil_03/leis/L9605.htm>. Acesso em: 01 jun. 2017.

BRASIL. Lei 5.197/67. Dispõe sobre a proteção à fauna e dá outras providências. Disponível em <www.senado.gov.br/sf/legislacao/const/...05.10.../CON1988.pdf ->Acesso em: 01 jun. 2017.

CORREIA, Laurinda Teodora. Crimes ambientais contra a fauna à luz da Lei no 9.605/98.

Universidade Salgado De Oliveira, 2009. Disponível em :

<http://www.revista.universo.edu.br/index.php/1direitoconstrucao3/article/viewPDFInterstitial/5 1/50>. Acesso em: 03 jun. 2017.

DUARTE, José; BARROS, Antônio (Orgs.). Métodos e técnicas de pesquisa em comunicação. 2. ed. São Paulo: Atlas, 2009.

GODINHO, Helena Telino Neves. A tutela jurídica da fauna terrestre: uma abordagem comparada dos ordenamentos português e brasileiro. In: FREITAS, Vladimir Passos. Direito ambiental em evolução, n 5., 3 ed. reimpr. Curitiba: Juruá, 2011.

LAKATOS, Eva M.; MARCONI, Marina A. Fundamentos de metodologia científica. 6. ed. 3. reimpr. São Paulo: Atlas, 2006.

LEVAI, Laerte Fernando. Proteção jurídica da fauna. Manual Prático da Promotoria de Justiça do Meio Ambiente. São Paulo: Imprensa Oficial, 2008.

LOURDES, Sérgio Lopes; MIRANDA, Marcos Paulo de Souza. Considerações acerca da nova Lei de Crimes Ambientais. Revista Jus Navigandi, Teresina, ano 3, №. 27, 23 de dezembro de 1998.

LOURENÇO, Daniel Braga. Direito dos animais: fundamentos e perspectiva. Porto Alegre: Sergio Antônio Fabris, 2008.

MACHADO, Paulo Affonso Leme. Direito Ambiental Brasileiro. 21. ed., rev., atual. e ampl., de acordo com as Leis 12.651/2012 e 12.727/2012 e com o Decreto 7.830/2012. São Paulo: Malheiros, 2013.

MARTINS, Renata de Freitas. Direitos dos Animais: Considerações legais sobre os crimes contra a fauna, aplicabilidade e efetividade das penas. Associação Santuário Ecológico Rancho dos Gnomos, 2008. Disponível em: <http://www.ranchodosgnomos.org.br/crimescontrafauna>. 03 ago. 2017.

MIGLIARI JUNIOR, Arthur. Crimes Ambientais. 2. ed. Campinas, SP: CS Edições Ltda. 2004. 
MILARÉ, Édis. Direito do Ambiente: a gestão ambiental em foco. Doutrina. Jurisprudência.

Glossário. 5. ed. São Paulo: Revista dos Tribunais, 2007.

RAMOS, Edson Pereira. Crimes contra o Meio Ambiente. Revista Jus Navigandi, Teresina, ano 5, no. 43, 1ㅇde julho de 2000. 